\title{
Staphylococcal enterotoxin M induced inflammation and impairment of bovine mammary epithelial cells
}

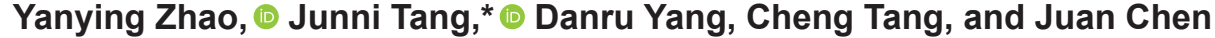 \\ Key Laboratory of Qinghai-Tibetan Plateau, Animal Genetic Resource Reservation and Utilization of Ministry of Education, \\ College of Life Science and Technology, Southwest Minzu University, Chengdu, China, 610041
}

\begin{abstract}
Staphylococcus aureus is one of the major etiological pathogens of bovine mastitis. Its invasion into mammary epithelial cells has been proven to be a key event in the pathogenesis of mastitis. However, the specific pathogenic factors have not been clearly identified. Staphylococcus aureus often triggers infections by releasing virulence factor. Recent several studies reported that staphylococcal enterotoxin $\mathrm{M}$ was one of the most frequently found enterotoxin genes associated with bovine mastitis. Thus, the effect of staphylococcal enterotoxin $\mathrm{M}$ on inflammation and damage of the bovine mammary epithelial bovine mammary gland epithelial cell line (MAC-T) cells with $48 \mathrm{~h}$ treatment was explored in the present study. First, staphylococcal enterotoxin M protein was purified by a Ni-NTA spin column (GE Life Science, Westborough, MA). The levels of tumor necrosis factor- $\alpha$, IL-6, and monocyte chemoattractant protein 1 (MCP-1) secretion were measured with the corresponding ELISA kits (R\&D Systems, Abingdon, UK). Second, cell viability was assessed with a Cell Counting Kit-8 (Bioswamp, Wuhan, China) and the apoptotic percentage of cells was determined by annexin V-fluorescein isothiocyanate (FITC)/propidium iodide (PI; Beyotime, Nanjing, China) staining. Third, ATP concentration, reactive oxygen species (ROS) generation and lactate dehydrogenase $(\mathrm{LDH})$ release were assayed with commercial kits, then mitochondrial membrane potential $(\Delta \Psi \mathrm{m})$ was estimated using fluorescent probe JC-1 (Beyotime). Finally, the production intercellular cell adhesion molecule-1 (ICAM-1), microtubule-associated protein 1A/1B-light chain $3 \mathrm{I} /$ II (LC3 I/II), p62 (Proteintech, Rosemont, IL), and phosphorylation of $\mathrm{I} \kappa \mathrm{B} \alpha$, caspase 3 , and mammalian target of rapamycin were detected by Western blot. The results showed that staphylococcal enterotoxin M
\end{abstract}

Received August 13, 2019.

Accepted April 20, 2020.

*Corresponding author: junneytang@aliyun.com induced inflammation of epithelial cells (upregulating tumor necrosis factor- $\alpha$, IL-6, MCP-1, and ICAM-1 production) and activated NF- $\kappa \mathrm{B}$ (promoting phosphorylation of $\mathrm{I} \kappa \mathrm{B} \alpha$ ). Furthermore, staphylococcal enterotoxin M impaired MAC-T cells via cell necrosis (enhancing LDH release), apoptosis (annexin V-FITC/ PI stain, exacerbating oxidative stress, decreasing $\Delta \Psi \mathrm{m}$ and intracellular ATP concentration, and activating caspase 3), but independent of autophagy (nonsignificantly increasing LC3-II, decreasing p62 expression, and activating mammalian target of rapamycin). Thereby, staphylococcal enterotoxin $\mathrm{M}$ induced the inflammatory property of bovine mammary epithelial cells by boosting cytokine, chemokine, and adhesion molecule production. Furthermore, it caused epithelial cell dysfunction via depressing cell viability and initiating cell necrosis and apoptosis. Because epithelial cells played important roles in orchestrating the inflammatory response and protecting bovine mammary tissue from mastitis, our results indicated that staphylococcal enterotoxin M may be associated with mastitis.

Key words: staphylococcal enterotoxin M, bovine mammary epithelial cell, mastitis, apoptosis

\section{INTRODUCTION}

Bovine mastitis induced by invading pathogens imposes considerable economic loss on the dairy industry worldwide through increased veterinary costs, reduced milk yield, and impaired milk quality (Viguier et al., 2009). The mammary gland is a complex organ composed of several cell types for synthesis and secretion of milk (Kobayashi and Kumura, 2011). Among the cells, a layer of mammary epithelial cells establishes the blood-milk barrier for exchange of macromolecules and solutes during milk production (Guidry et al., 1998). Upon bacterial challenge, mammary epithelial cells protect the underlying tissues from damage via eliciting proinflammatory cytokines and triggering the inflammatory cascade response in the acute phase of mastitis (Günther et al., 2011). Unfortunately, mammary epithelial cell dysfunction caused by exacerbated 
or sustained inflammation damages barrier integrity and surrounding extravascular tissues (Ryman et al., 2015). Given the important role of epithelial cells in regulating mammary gland health and disease, a better understanding of epithelial cell function during mastitis may support development of targeted therapies to protect mammary tissue.

Staphylococcus aureus is one of the major etiological pathogens of bovine mastitis (Piccinini et al., 2012). Staphylococcus aureus adhesion and invasion to mammary epithelial cells have been proven to be key events involved in the pathogenesis of mastitis (Kerro Dego et al., 2002). Following S. aureus infection, the cells recognize $S$. aureus through the plasma membrane toll-like receptor 2 . The binding activates the phosphoinositide 3-kinase/Akt (PI3K/Akt)-mammalian target of rapamycin (mTOR) signaling pathway that mediates a variety of cellular responses such as survival, proliferation, apoptosis, and inflammation (Akira and Takeda, 2004), but the specific pathogenic factors in $S$. aureus leading to mastitis have not been clearly identified. Staphylococcus aureus often triggers infections by releasing virulence factors such as enterotoxins, a series of related proteins responsible for toxic-shock syndrome, septicemia, and food poisoning (Casman, 1965; Balaban and Rasooly, 2000). Staphylococcal enterotoxins have been traditionally subdivided into classical staphylococcal enterotoxins (from SEA to SEE) and newly identified staphylococcal enterotoxins or enterotoxin-like proteins (SEl; through SEG to SEIY; Argudín et al., 2010; Hu and Nakane, 2014). Recent several studies established the virulence gene profiles of $S$. aureus isolates collected from milk samples of cows with subclinical or clinical mastitis. These toxin genes were reported to be closely associated with the pathogenicity of the $S$. aureus causing mastitis (Wang et al., 2017). In particular, staphylococcal enterotoxin M was harbored by $19.4 \%$ S. aureus isolates in eastern Poland (Kot et al., 2016), by $26.9 \%$ S. aureus isolates in 2 major diary production regions of China (Wang et al., 2009), by $16.0 \%$ S. aureus strains in 10 dairy herds located in Ningxia, China (Wang et al., 2017), by $100 \%$ S. aureus ST520 strains from 2014 to 2015 in the Shanghai and Zhejiang areas of China (Li et al., 2017), and by $100 \%$ methicillin-resistant $S$. aureus strains from 5 dairy farms in Gyeonggi province in Korea from 2011 to 2012 (Song et al., 2016). The frequent occurrence of the staphylococcal enterotoxin $M$ gene associated with mastitis indicated that it might be related to mastitis. Because epithelial cells played important roles in orchestrating the inflammatory response and protecting bovine mammary tissue from mastitis, the present study investigated the possible effect of staphylococcal enterotoxin $\mathrm{M}$ on inflammatory response and survival of bovine mammary epithelial cells.

\section{MATERIALS AND METHODS}

\section{Staphylococcal Enterotoxin M Protein Preparation}

Staphylococcal enterotoxin M protein was prepared as we previously described (Zhao et al., 2017). In brief, staphylococcal enterotoxin $M$ gene was amplified from clinical S. aureus strain $\mathrm{H} 4$ associated with food poisoning. Then staphylococcal enterotoxin $\mathrm{M}$ gene was cloned into pET-28a plasmid (Novagen, Darmstadt, Germany) and transformed into competent Escherichia coli BL21 (DE3) cells (Novagen). After induction with $0.5 \mathrm{mmol} / \mathrm{L}$ isopropyl-1-thio- $\beta$-D-galactopyranoside (Sigma-Aldrich, St. Louis, MO), the cells were lysed by sonication and the tagged staphylococcal enterotoxin $\mathrm{M}$ recombinant protein was purified by a Ni-NTA spin column (GE Life Science, Westborough, MA). At last, the purified protein was dialyzed into $10 \mathrm{mmol} / \mathrm{L} \mathrm{PBS}$ $(\mathrm{pH}=7.4)$ and applied to $12 \%$ SDS-PAGE.

\section{Cell Culture and Treatment}

The bovine mammary gland epithelial cell line MAC$\mathrm{T}$ was a kind gift from Jinfeng Miao (Nanjing Agricultural University, Nanjing, China). The MAC-T cell line was established from primary bovine mammary alveolar cells by stable transfection with SV-40 large T-antigen. The cells displayed a cobblestone shape on plastic substratum. They are widely used to investigate inflammation and proliferation assay of bovine mammary epithelial cells associated with mastitis (Jeong et al., 2017; Wang et al., 2019). In the present study, monolayer MAC-T cells were grown in high glucose Dulbecco's modified Eagle's medium (Hyclone, Fremont, CA) supplemented with $10 \%$ fetal bovine serum (Gibco, Waltham, MA), $100 \mathrm{U} / \mathrm{mL}$ streptomycin, and $100 \mathrm{U} / \mathrm{mL}$ penicillin in the humidified atmosphere of $5 \% \mathrm{CO}_{2}$ at $37^{\circ} \mathrm{C}$. For assays, in vitro cultured MAC-T cells between passages 25 and 30 were serum-starved for $24 \mathrm{~h}$ before treatment and then incubated in the presence of $0,1,100$, and $10,000 \mu \mathrm{g} / \mathrm{L}$ staphylococcal enterotoxin $\mathrm{M}$ for $48 \mathrm{~h}$.

\section{Cell Viability Assay}

The effect of staphylococcal enterotoxin $\mathrm{M}$ on bovine mammary gland epithelial cell viability was assessed with a Cell Counting Kit-8 (CCK8, no. 1706, Bioswamp, Wuhan, China). In detail, $3 \times 10^{3}$ cells/well was inoculated and exposed to $0,1,100$, and 10,000 
$\mu \mathrm{g} / \mathrm{L}$ staphylococcal enterotoxin $\mathrm{M}$ for $48 \mathrm{~h}$ as above, then $10 \mu \mathrm{L}$ of CCK8 solution was added for $4 \mathrm{~h}$ and the absorbance value was calculated at $450 \mathrm{~nm}$. The data were expressed as the percentage of viable cells with staphylococcal enterotoxin $\mathrm{M}$ treatment compared with that in the control group.

\section{Cell Apoptosis, Reactive Oxygen Species Production, and Inflammatory Cytokine Release}

After being challenged with staphylococcal enterotoxin $\mathrm{M}$ for $48 \mathrm{~h}$, bovine mammary epithelial cells were stained with an annexin V-fluorescein isothiocyanate (FITC)/propidium iodide (PI) apoptosis assay kit according to the manufacturer's protocol (no. C1062, Beyotime, Nanjing, China). The percentage of cells at different apoptotic stages was determined by a flow cytometer (Beckman Coulter FC500, Brea, CA). At the same time, the reactive oxygen species (ROS) generation by the cells was measured with a cellular ROS detection assay kit (no. PAB180052, Bioswamp), and also analyzed by the flow cytometer. In addition, the concentrations of tumor necrosis factor- $\alpha$ (TNF- $\alpha$, no. HM10001, Bioswamp), IL-6 (no. HM10205, Bioswamp), and monocyte chemoattractant protein 1 (MCP-1, no. HM10894, Bioswamp) secreted from bovine mammary epithelial cells were assayed using the corresponding ELISA kits (R\&D Systems, Abingdon, UK).

\section{Lactate Dehydrogenase Release}

Lactate dehydrogenase (LDH) is an enzyme that is normally located in the cytoplasm and is released into the medium when the cell membrane is damaged (Loeffler et al., 2004). Thus, LDH release assay can be used to evaluate the integrity of cell membranes. After staphylococcal enterotoxin M treatment, the cell supernatants were collected for measurement of LDH release by a LDH Assay Kit (no. A020-1, Nanjing Jiancheng Chemical Industrial Co. Ltd., Nanjing, China). Then, the absorbance at $490 \mathrm{~nm}$ was detected.

\section{Assessment of Mitochondrial Membrane Potential and Intracellular ATP Content}

Mitochondrial membrane potential was estimated using fluorescent probe JC-1 (no. 180068, Beyotime, Nanjing, China) as described previously (Feng et al., 2017). The JC-1 monomer and aggregate signals were detected by flow cytometry analysis and the ratio of aggregate/ monomer fluorescent intensity was calculated for the level of mitochondrial membrane potential. Intracellular ATP concentrations were assayed with an ATP assay kit (no. A095, Nanjing Jiancheng Chemical Industrial
Co. Ltd.). The cells were lysed and the proteins were discarded. Then, using ATP as standard, intracellular ATP contents were determined by chemiluminescence (West Pico kit, Pierce, Loughborough, UK).

\section{Western Blot}

Western blot was employed to measure phosphorylation of $\mathrm{I} \kappa \mathrm{B} \alpha$, caspase $3, \mathrm{mTOR}$, and the levels of intercellular cell adhesion molecule-1 (ICAM-1), microtubule-associated protein 1A/1B-light chain $3 \mathrm{I} / \mathrm{II}$ (LC3 I/II), and p62 in bovine mammary epithelial cells with staphylococcal enterotoxin $\mathrm{M}$ challenge. Total cellular and cytoplasmic proteins were prepared with lysis buffer containing protease and phosphatase inhibitors (Sigma-Aldrich) and applied to SDS-PAGE, transferred to nitrocellulose membranes (Whatman, London, UK). Then, the membranes were blocked with $20 \mathrm{mmol} / \mathrm{L}$ Tris-HCl buffer supplemented with $0.1 \%$ Tween 20 and $5 \% \mathrm{wt} / \mathrm{vol} \mathrm{BSA}$ for $1 \mathrm{~h}$ at room temperature. After that, the proteins on the membranes were incubated overnight at $4^{\circ} \mathrm{C}$ with the specific primary antibodies

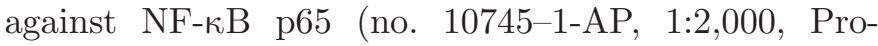

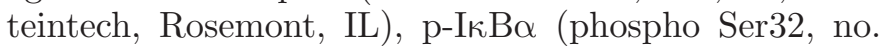
ab92700, 1:2,000, Abcam, Cambridge, MA), caspase 3 (no. 19677-1-AP, 1:1,000, Proteintech), p-caspase 3 (phospho S150, no. ab59425, 1:1,000, Abcam), mTOR (no. 0657-1-AP, 1:1,000, Proteintech), p-mTOR (phospho S2448, no. ab109265, 1:1,000, Abcam), ICAM-1 (no. 10020-1-AP, 1:2000, Proteintech), LC3 I/II (no. 128,025, 1:1,000, Abcam), p62 (no. 18420-1-AP, 1:2,000, Proteintech), and GAPDH (no. PAB36269, 1:1,000, Bioswamp). Membranes were washed 3 times and the corresponding horseradish peroxidase-conjugated secondary antibodies were added. Finally, specific immune blots were detected by chemiluminescence (West Pico kit, Pierce). The values from Western blot assay were expressed as the percentage of optical density with staphylococcal enterotoxin $\mathrm{M}$ treatment groups compared with that in the control group.

\section{Statistical Analysis}

The data were presented as average values \pm standard error of the means from 3 independent experiments of cell viability assay, cell apoptosis, ROS production, inflammatory cytokine, LDH release, mitochondrial membrane potential $(\Delta \mathbf{\Psi m})$, intracellular ATP content, and Western blot analysis. Statistical analyses were performed with SPSS Statistics V17.0 software (SPSS Inc., Chicago, IL). These data were checked for normal distribution using Shapiro-Wilk test and the differences between 1,100 , or 10,000 $\mu \mathrm{g} / \mathrm{L}$ staphylococcal enterotoxin $\mathrm{M}$ treatment groups and the control 
group were made by an unpaired $t$-test with $95 \%$ confidence intervals. Statistical significance was considered at 2 -tailed value of $P<0.05$.

\section{RESULTS}

\section{Staphylococcal Enterotoxin M Protein Preparation}

The identified staphylococcal enterotoxin $\mathrm{M}$ gene information was submitted to GenBank (GenBank accession number: KT853047). The entire nucleotide sequence encoded a 239 amino acid polypeptide precursor. Molecular weight of the deduced protein was 27.37 $\mathrm{kDa}$. Thereafter, mature staphylococcal enterotoxin $\mathrm{M}$ protein was expressed in E. coli BL21 cells and purified by $\mathrm{Ni}^{2+}$-charged affinity chromatography. The purified protein with expected molecular weight (about $28 \mathrm{kDa}$ ) is indicated by an arrow in Figure 1.

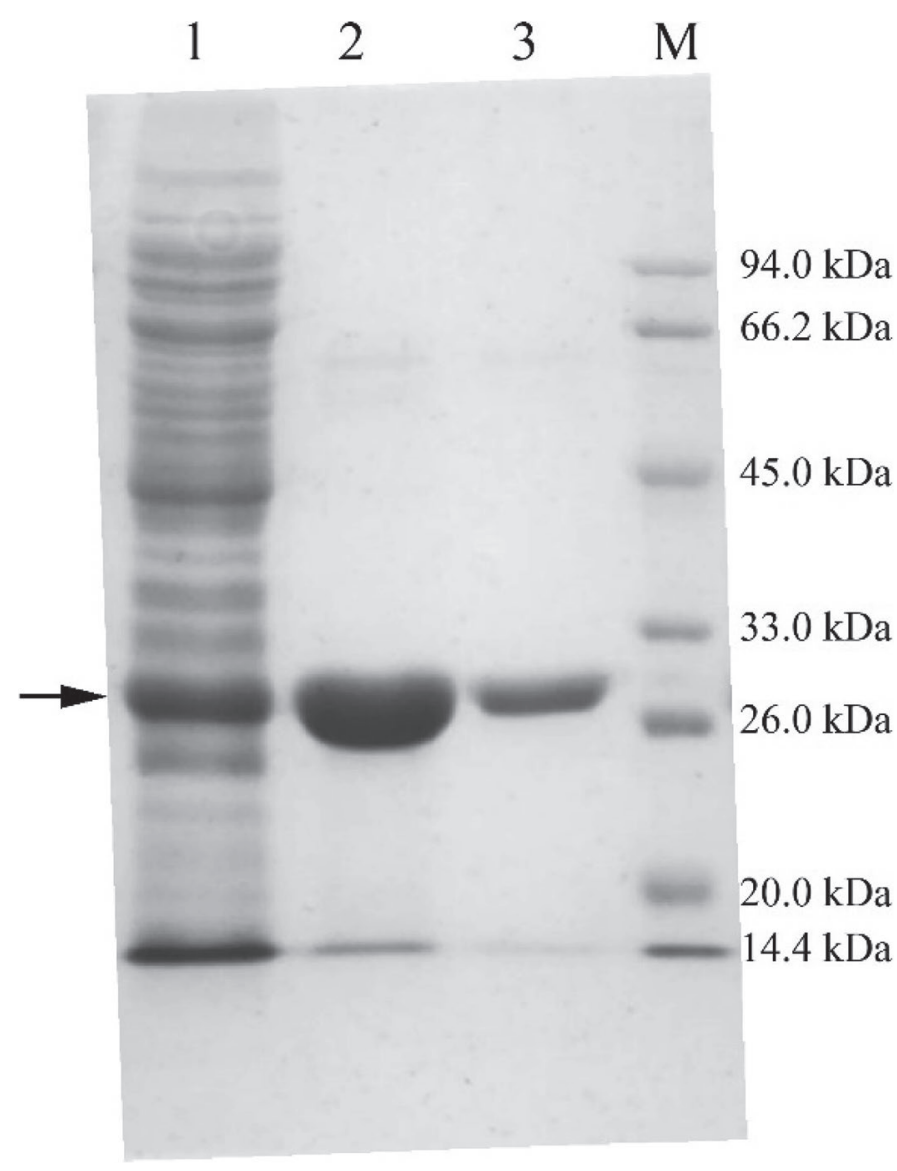

Figure 1. Preparation of staphylococcal enterotoxin M protein. The fractions purified by $\mathrm{Ni}^{2+}$-charged affinity chromatography were applied to SDS-PAGE. (1) Cellular total proteins after induction by isopropyl-1-thio- 3 -D-galactopyranoside; (2) fraction elution with 50 $\mathrm{mmol} / \mathrm{L}$ imidazole; and (3) fraction elution with $100 \mathrm{mmol} / \mathrm{L}$ imidazole. The target protein with expected molecular weight (about 28 $\mathrm{kDa}$ ), indicated by an arrow, was collected. $\mathrm{M}=$ marker.

\section{Inflammatory Response in Mammary Epithelial Cells}

Mammary epithelial cells with mastitis express proinflammatory cytokines including TNF- $\alpha$ and IL-6 (Zhang et al., 2016). The present study investigated whether staphylococcal enterotoxin $\mathrm{M}$ mediated the secretion of TNF- $\alpha$ and IL-6 in bovine mammary epithelial cells. Results shown that staphylococcal enterotoxin M potentially promoted TNF- $\alpha$ and IL-6 secretion (Figure 2A, B). Furthermore, staphylococcal enterotoxin M enhanced ICAM-1 and MCP-1 production (Figure 2C, D, E); ICAM-1 is an endothelial- and leukocyte-associated transmembrane protein facilitating leukocyte endothelial transmigration (Yang et al., 2005), whereas MCP-1 is a highly potent chemoattractant protein inducing monocytes and macrophages to sites of tissue injury and inflammatory reaction (Yadav et al., 2010). Thus, staphylococcal enterotoxin M induced proinflammatory cytokine release of bovine mammary epithelial cells, which might recruit monocytes and macrophages to the mammary gland. In addition, TNF- $\alpha$ and IL- 6 belong to key signaling molecules of the downstream NF- $\kappa \mathrm{B}$ signaling pathway (Huang et al., 2012). To understand the molecular mechanism of staphylococcal enterotoxin $\mathrm{M}$ induced expression of TNF- $\alpha$ and IL-6, the NF- $\kappa \mathrm{B}$ was analyzed by Western blot. As shown in Figure 2D, F, G, staphylococcal enterotoxin M boosted I $\mathrm{B} \alpha$ phosphorylation, which suggested that inflammation induced by staphylococcal enterotoxin $\mathrm{M}$ was probably

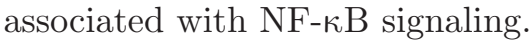

\section{Cell Viability}

As described above, exacerbated inflammation would induce epithelial dysfunction (Ryman et al., 2015), so CCK8 assay was used to test the effect of staphylococcal enterotoxin $\mathrm{M}$ on bovine mammary epithelial cell viability. After $48 \mathrm{~h}$ of treatment, 1, 100, and 10,000 $\mu \mathrm{g} / \mathrm{L}$ staphylococcal enterotoxin $M$ significantly inhibited cell viability $(P<0.001)$ in a dose-dependent manner as shown in Figure 3. The results indicated that staphylococcal enterotoxin $\mathrm{M}$ depressed epithelial cell viability, which would lead to cell death.

\section{Integrity of Mammary Epithelial Cell Membrane}

Cell death, the ultimate consequence of infection, mainly includes cell necrosis, apoptosis, and autophagy (Orrenius et al., 2011). Necrosis is characterized by loss of cell membrane integrity and release of cellular contents such as LDH. Thus, the activity of LDH in cell medium was determined by a LDH Assay Kit as shown in Figure 4. Staphylococcal enterotoxin M increased 
LDH release, indicating that it impaired mammary epithelial cell membrane integrity and led to cell necrosis.

\section{Cell Apoptosis}

Cell apoptosis was investigated using annexin VFITC/PI staining. The results in Figure 5 revealed that staphylococcal enterotoxin M significantly enhanced mammary epithelial cell apoptosis. Cell apoptosis is mainly mediated through the intrinsic and extrinsic apoptosis pathway. Excessive ROS can induce apoptosis through both the extrinsic and intrinsic pathways (Lamkanfi and Dixit, 2010). In the present study, staphylococcal enterotoxin M promoted ROS production (Figure 6A). In addition, mitochondrial membrane potential and intracellular ATP content were assessed in Figures 6B and 6C. Staphylococcal enterotoxin M impaired mitochondrial membrane potential and further decreased intracellular ATP concentration. These data indicated staphylococcal enterotoxin M depressed
A

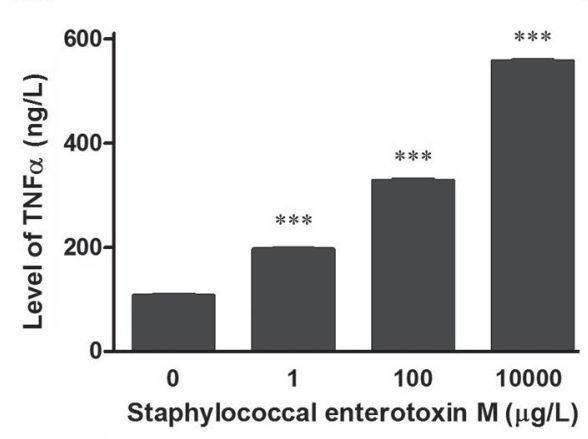

D

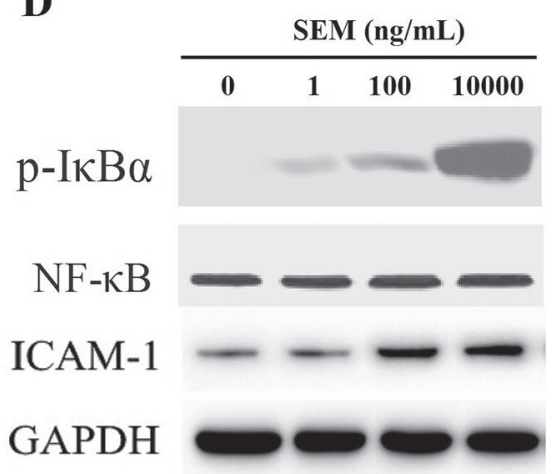

B

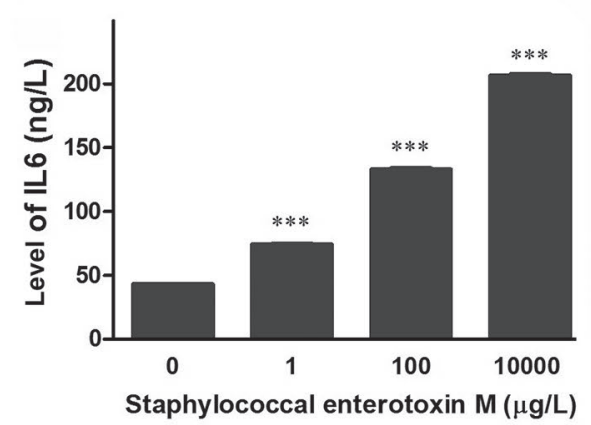

E

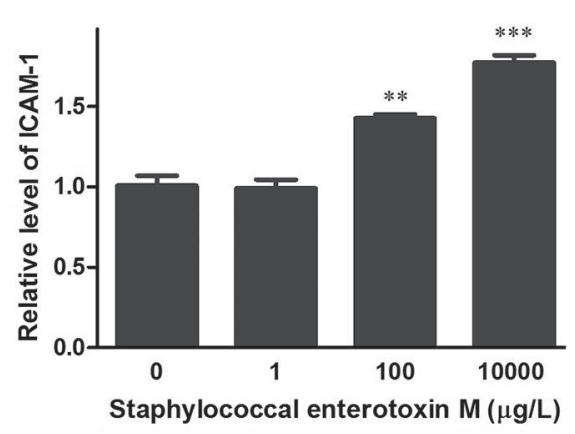

C

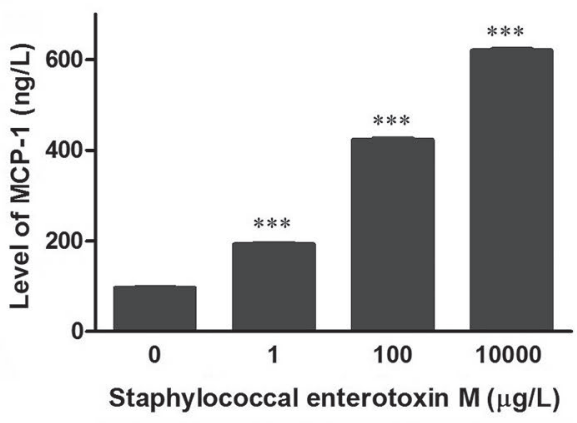

$\mathbf{F}$

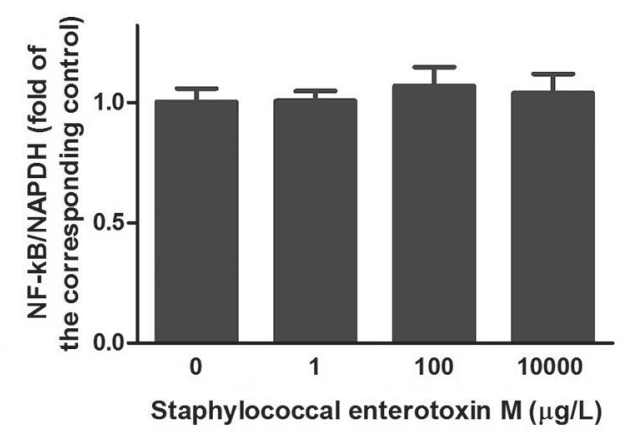

\section{G}

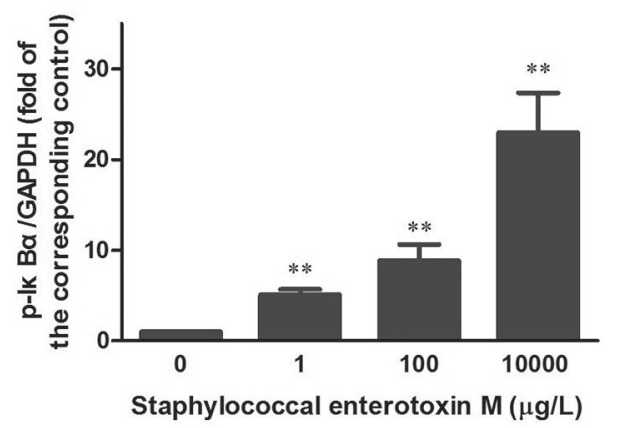

Figure 2. Inflammatory response in mammary epithelial cell cytokines. The bovine mammary gland epithelial cells were exposed for $48 \mathrm{~h}$ to 0, 1, 100, and 10,000 $\mathrm{mg} / \mathrm{L}$ staphylococcal enterotoxin M. Then, the concentrations of tumor necrosis factor- $\alpha$ (TNF- $\alpha$; A), IL6 (B), and monocyte chemoattractant protein 1 (MCP-1; C) secreted were measured using the corresponding ELISA kits. The level of the production intercellular

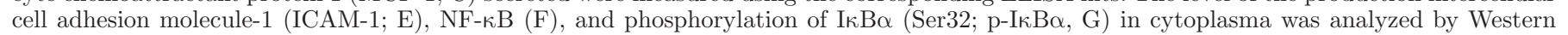
blot. Data were the mean $\pm \mathrm{SEM}$ of 3 independent experiments. ${ }^{* *} P<0.01,{ }^{* * *} P<0.001$. 


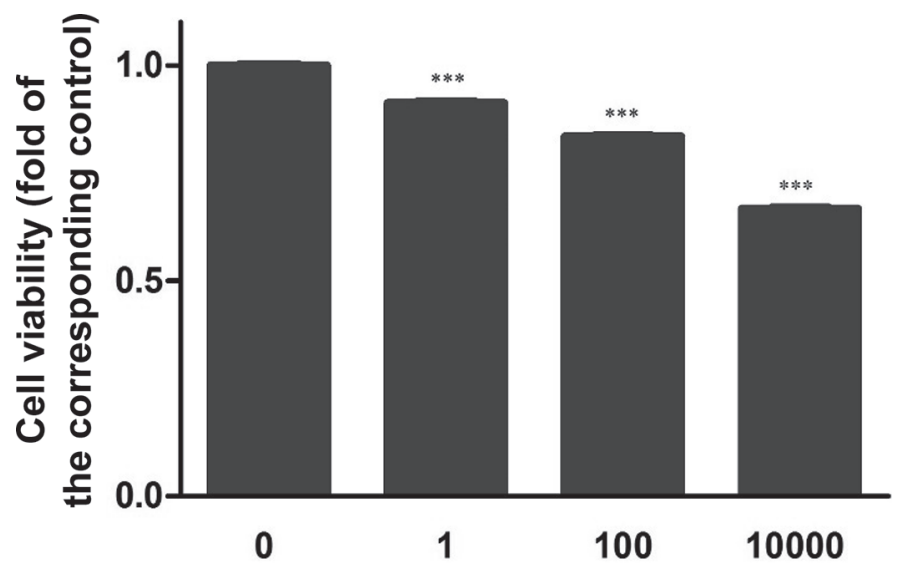

Staphylococcal enterotoxin $M(\mu \mathrm{g} / \mathrm{L})$

Figure 3. Viability of mammary epithelial cells. Three $\times 10^{3}$ cells/ well was inoculated and exposed to $0,1,100$, and $10,000 \mu \mathrm{g} / \mathrm{L}$ staphylococcal enterotoxin $\mathrm{M}$ for $48 \mathrm{~h}$ as above. Then, $10 \mu \mathrm{L}$ of Cell Counting Kit-8 (Bioswamp, Wuhan, China) solution was added for $4 \mathrm{~h}$, and the absorbance value was calculated at $450 \mathrm{~nm}$. The data were expressed as the percentage of viable cells with staphylococcal enterotoxin $\mathrm{M}$ treatment compared with that in the control group. Data were the mean \pm SEM of 3 independent experiments. ${ }^{* * *} P<0.001$.

mitochondrial function. Furthermore, it activated caspase-3 (Figure 6D). Caspase-3 is essential for the formation of apoptotic bodies (Porter and Jänicke, 1999). Therefore, staphylococcal enterotoxin $\mathrm{M}$ probably depressed mammary epithelial cell viability via the cell apoptosis pathway.

\section{Cell Autophagy}

Cell death can also occur as a result of cell autophagy. During cell autophagy processes, LC3-I is conjugated to phosphatidylethanolamine to form LC3-II. Thus, detecting LC3-II/I by immunoblotting has become a reliable method for monitoring autophagy (Tanida et al., 2008). In this study, staphylococcal enterotoxin $M$ did not significantly activate LC3-II (Figure 7A). Consistent with this, the level of the selective autophagy receptor p62 did not change (Figure 7B). Given that mTOR is a major regulator of cell autophagy, mTOR activity after staphylococcal enterotoxin $\mathrm{M}$ stimulation was investigated. Staphylococcal enterotoxin M did not regulate mTOR activity either (Figure 7D). Therefore, staphylococcal enterotoxin $\mathrm{M}$ did not obviously induce mammary epithelial cell autophagy.

\section{DISCUSSION}

Staphylococcus aureus is one of the most important pathogens inducing bovine mastitis. It has been proved

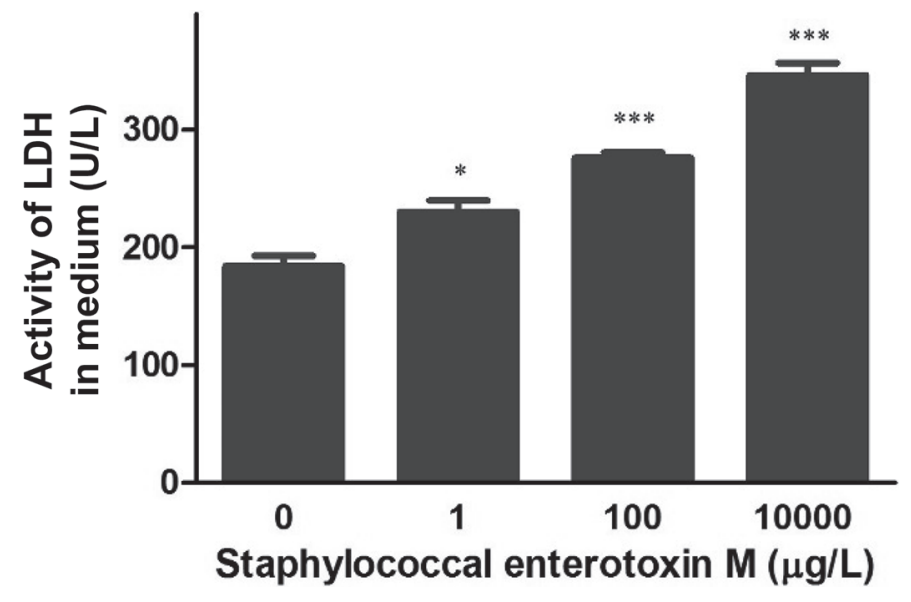

Figure 4. Lactate dehydrogenase $(\mathrm{LDH})$ release from mammary epithelial cells. After $0,1,100$, and 10,000 $\mu \mathrm{g} / \mathrm{L}$ staphylococcal enterotoxin $\mathrm{M}$ treatment for $48 \mathrm{~h}$, the supernatants of mammary gland epithelial cells were collected for measurement of $\mathrm{LDH}$ release by a $\mathrm{LDH}$ Assay Kit (Nanjing Jiancheng Chemical Industrial Co. Ltd., Nanjing, China). The absorbance at $490 \mathrm{~nm}$ was detected. Data were the mean \pm SEM of 3 independent experiments. ${ }^{*} P<0.05,{ }^{* * *} P<0.001$.

that mammary epithelial cells are the main targets of $S$. aureus infection in bovine mastitis (Kerro Dego et al., 2002). However, the pathogen effectors have not been clearly elucidated. More than one report indicated the occurrence of the staphylococcal enterotoxin $\mathrm{M}$ gene in $S$. aureus isolate associated with mastitis (Piccinini et al., 2012; Song et al., 2016; Li et al., 2017). Thus, the distinctive role of staphylococcal enterotoxin $\mathrm{M}$ on mammary epithelial cells was explored in the present study.

Upon S. aureus challenge, mammary epithelial cells secrete chemokines and cytokines, recruiting and activating leukocytes to target sites against pathogens in mastitis (Alluwaimi, 2004). Here, staphylococcal enterotoxin M upregulated proinflammatory cytokines TNF- $\alpha$ and IL-6, chemokine MCP-1, and adhesion molecule ICAM-1 production. It has been reported that cytokines, such as TNF- $\alpha$ and IL-6, and chemokines, such as MCP-1, play important roles in the pathogenesis of mastitis (Kim et al., 2011). Elevated concentrations of chemokines induce the migration of inflammatory leukocytes to the infected area (Geng, 2001), and the cytokines amplify the inflammatory response. Moreover, activation of NF- $\kappa \mathrm{B}$ further causes the release of inflammatory cytokines and chemokines ( $\mathrm{Li}$ et al., 2019). Then, sustained inflammatory reaction induces epithelial cell dysfunction (Ryman et al., 2015).

The blood-milk barrier formed by mammary epithelial cells is important for mammary gland resistance to bacterial infection and destruction of the bloodmilk barrier aggravates the development of mastitis 
A

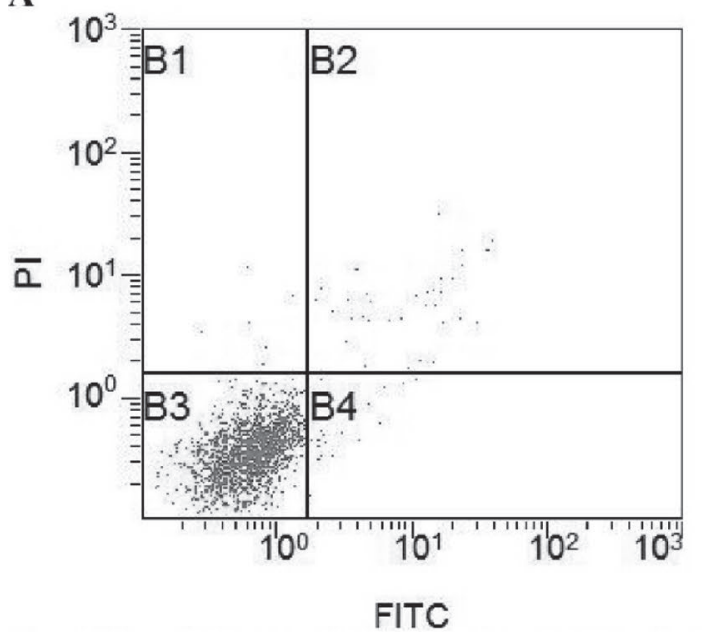

C

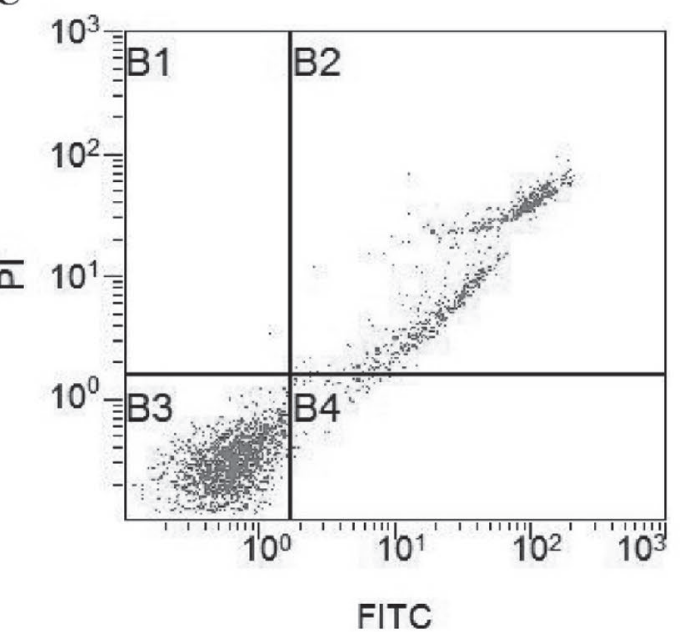

E

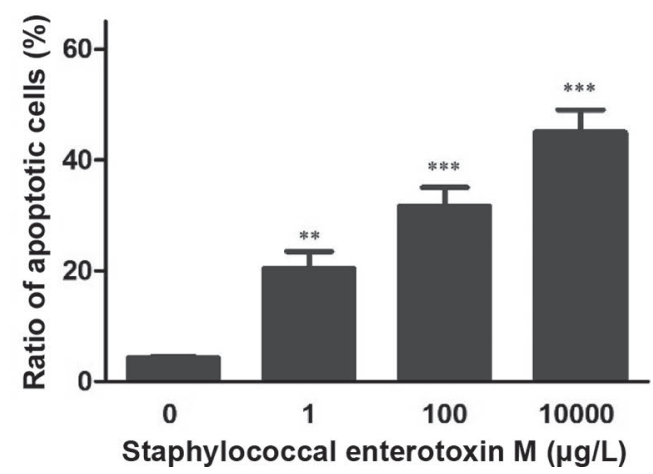

B

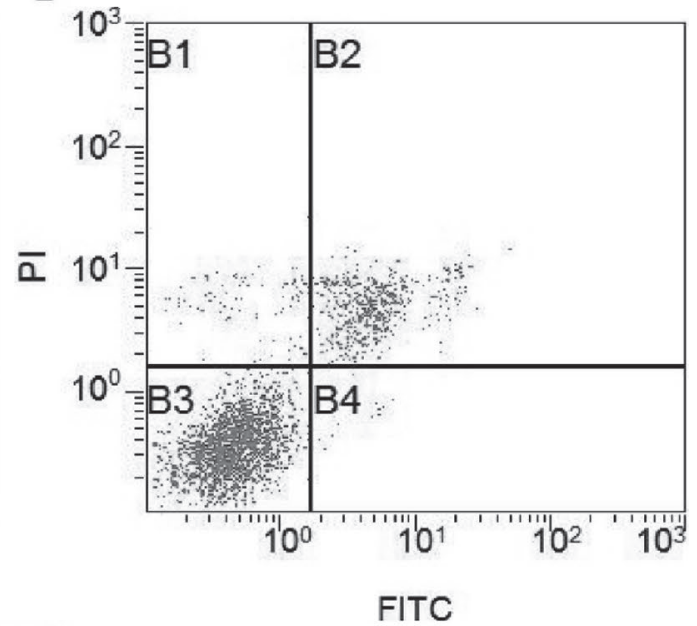

D

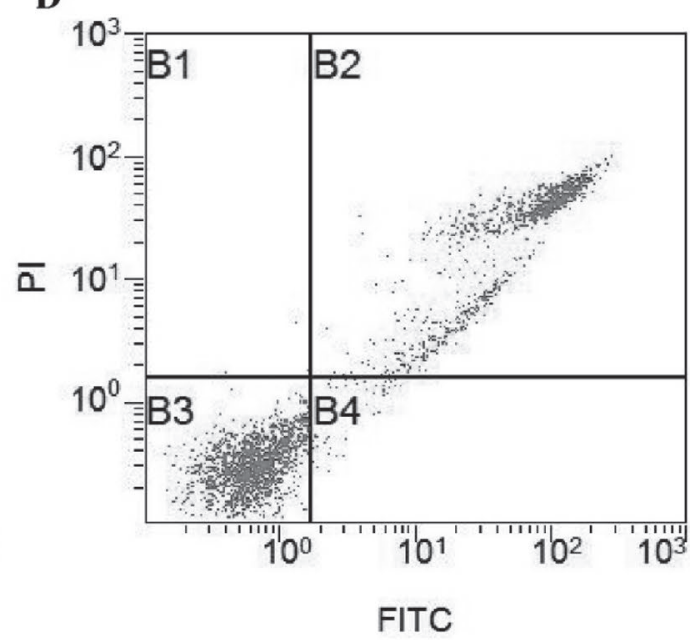

Figure 5. Cell apoptosis of mammary epithelial cells. After being treated with 0, 1, 100, and 10,000 $\mu \mathrm{g} / \mathrm{L}$ staphylococcal enterotoxin M for $48 \mathrm{~h}$, mammary epithelial cells were stained and apoptosis was analyzed with an annexin V-fluorescein isothiocyanate (FITC)/propidium iodide (PI) apoptosis assay kit (Beyotime, Nanjing, China) according to the manufacturer's protocol (https://www.beyotime.com/product/C1062S .htm). (A) Control, (B) $1 \mu \mathrm{g} / \mathrm{L}$ staphylococcal enterotoxin M, (C) $100 \mu \mathrm{g} / \mathrm{L}$ staphylococcal enterotoxin M, and (D) 10,000 $\mu \mathrm{g} / \mathrm{L}$ staphylococcal enterotoxin M. The cell percentage of different apoptotic stages was determined by a flow cytometer (Beckman Coulter FC500, Brea, CA; E). $\mathrm{B} 1=$ necrotic cells; B2 = cells at late apoptotic stage; B3 = live cells; B4 = cells at early apoptotic stage. Data were the mean \pm SEM of 3 independent experiments. ${ }^{* *} P<0.01$, ${ }^{* * *} P<0.001$. 
A

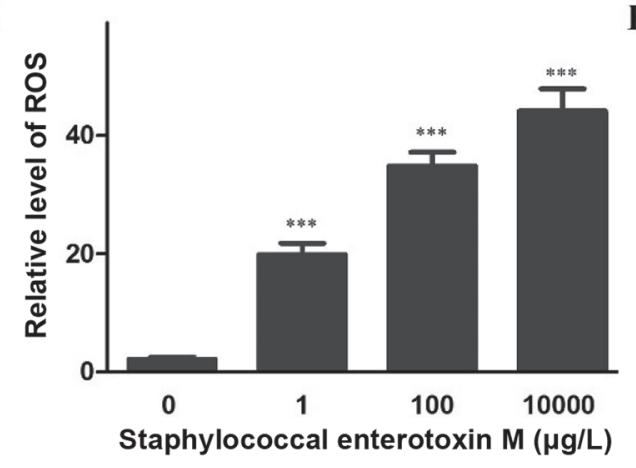

$\mathbf{B}$ 뜬

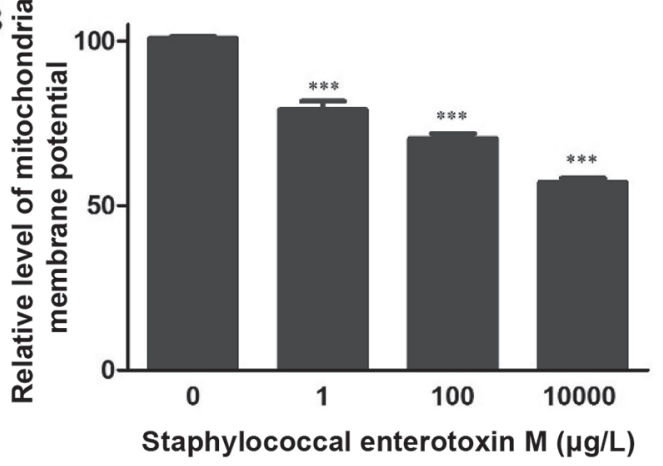

C

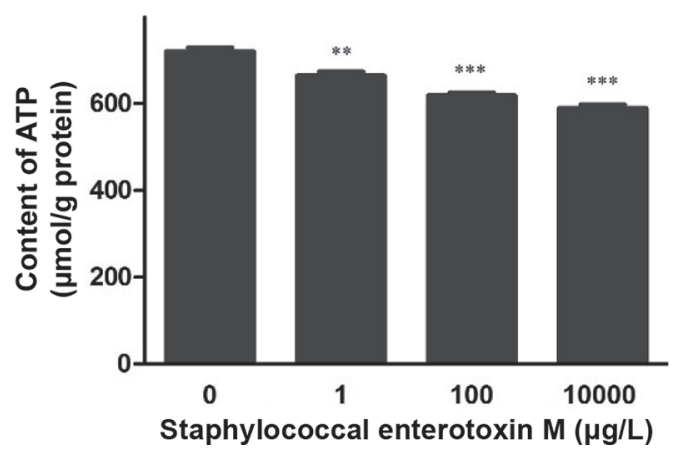

D

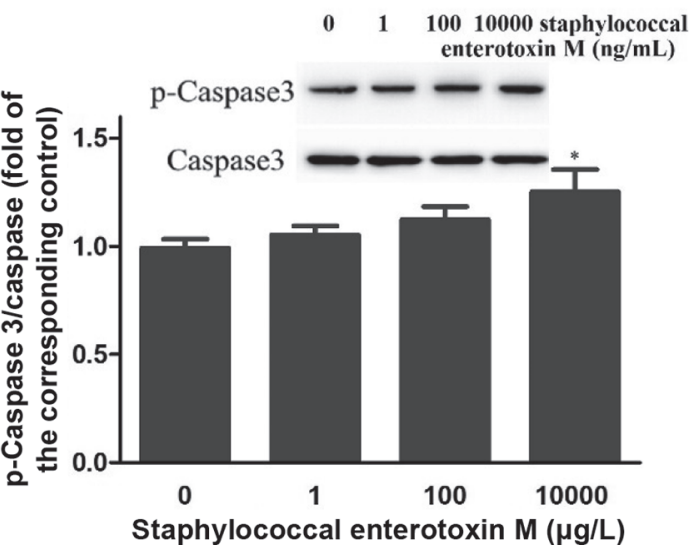

Figure 6. Mitochondrial apoptosis pathway of mammary epithelial cells. After staphylococcal enterotoxin $\mathrm{M}$ administration for $48 \mathrm{~h}$, the reactive oxygen species (ROS) production was measured with cellular reactive oxygen species detection assay kit, and analyzed by a flow cytometer (Beckman Coulter FC500, Brea, CA; A). Mitochondrial membrane potential was estimated using fluorescent probe JC-1 (Beyotime, Nanjing, China; B). Intracellular ATP concentrations were assayed with an ATP assay kit (Nanjing Jiancheng Chemical Industrial Co. Ltd., Nanjing, China; C). Phosphorylation of caspase 3 (p-caspase 3) was determined by Western blot (D). Data were the mean \pm SEM of 3 independent experiments. ${ }^{*} P<0.05,{ }^{* *} P<0.01,{ }^{* * *} P<0.001$.

(Bruckmaier and Wellnitz, 2017). In the current study, staphylococcal enterotoxin M impaired the integrity of mammary epithelial cells, which may be attributed to cell necrosis, apoptosis, or both. A further important finding of this study was that staphylococcal enterotoxin $\mathrm{M}$ induced apoptosis of the bovine mammary epithelial cells. In our previous study, staphylococcal enterotoxin $\mathrm{M}$ caused intestine dysfunction via inflammatory cell invasion and loss of epithelium, which was in consistent with the present observation (Zhao and Tang, 2018). Cell apoptosis and production of ROS are closely related. Excessive ROS can cause cell apoptosis through activating Fas and the caspase cascade, which is induced through mitochondrial damage (Maiuri et al., 2007). Staphylococcal enterotoxin $M$ enhanced ROS production and caspase-3 activation. Thus, the disruption was probably related to oxidative stress and mitochondrial damage with decreased mitochondrial membrane potential and intracellular ATP concentration. Oxidative response, cell apoptosis, autophagy, and inflammation constitute the major defense networks in cells against pathogens (Tang et al., 2014). On the other hand, our results indicated the impairment of mammary epithelial cells by staphylococcal enterotoxin $\mathrm{M}$ was independent of autophagy as evidenced by no obvious variation of LC-II/I or p62.

\section{CONCLUSIONS}

Staphylococcal enterotoxin M induced inflammation of mammary epithelial cells and further impaired epithelial cell viability by ROS production, cell necrosis, and apoptosis, which was independent of cell autophagy.

\section{ACKNOWLEDGMENTS}

This work was jointly supported by the National Key Research and Development Program of China (2018YFD0500500), the Applied Basic Research Programs of Sichuan Province (2019YJ0261), 
A
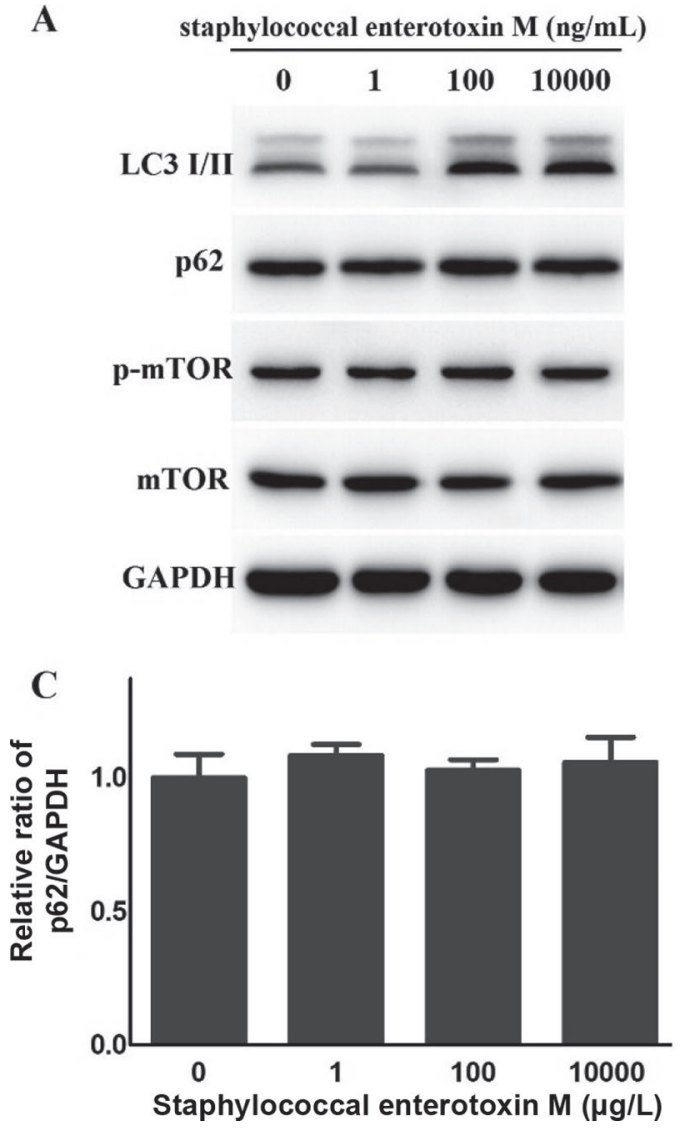

B
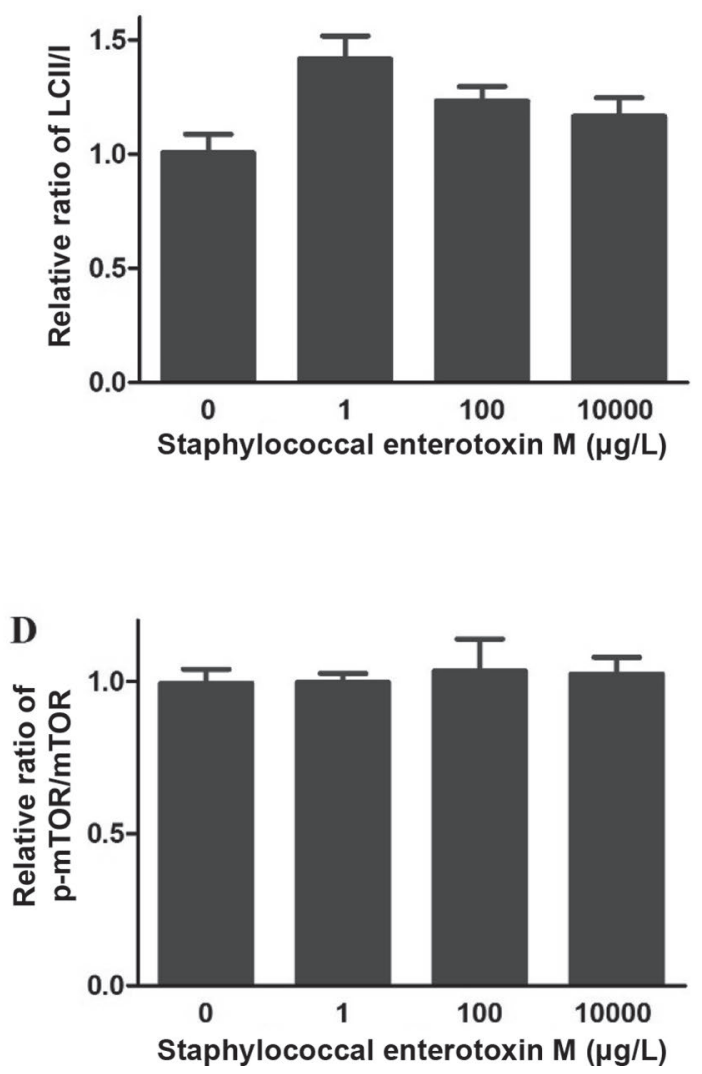

Figure 7. Autophagy of mammary epithelial cells. The mammary gland epithelial cells were exposed to 0 , 1,100, and $10,000 \mu \mathrm{g} / \mathrm{L}$ staphylo-

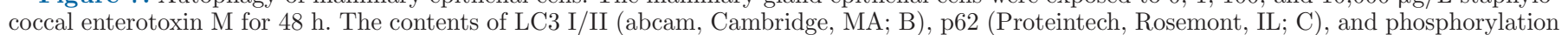

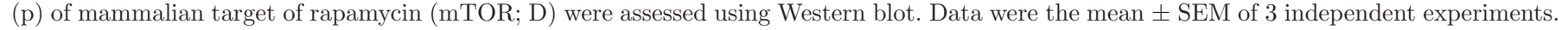

the Sichuan Province Science Funds for Distinguished Young Scholar (2019JDJQ0017), and the Fundamental Research Funds for the Central Universities, Southwest Minzu University (2019XMJXPY08). The authors declare that they have no competing interests.

\section{REFERENCES}

Akira, S., and K. Takeda. 2004. Toll-like receptor signaling. Nat. Rev. Immunol. 4:499-511. https://doi.org/10.1038/nri1391.

Alluwaimi, A. M. 2004. The cytokines of bovine mammary gland: Prospects for diagnosis and therapy. Res. Vet. Sci. 77:211-222. https://doi.org/10.1016/j.rvsc.2004.04.006.

Argudín, M. Á., M. C. Mendoza, and M. R. Rodicio. 2010. Food poisoning and Staphylococcus aureus enterotoxins. Toxins (Basel) 2:1751-1773. https://doi.org/10.3390/toxins2071751.

Balaban, N., and A. Rasooly. 2000. Staphylococcal enterotoxins. Int. J. Food Microbiol. 61:1-10. https://doi.org/10.1016/S0168 -1605(00)00377-9.

Bruckmaier, R. M., and O. Wellnitz. 2017. Triennial Lactation Symposium/BOLFA: Pathogen-specific immune response and changes in the blood-milk barrier of the bovine mammary gland. J. Anim. Sci. 95:5720-5728. https://doi.org/10.2527/jas2017.1845.

Casman, E. P. 1965. Staphylococcal enterotoxin. Ann. N. Y. Acad. Sci. 128:124-131. https://doi.org/10.1111/j.1749-6632.1965.tb11634.x.
Feng, F., Q. Ren, S. Wu, M. Saeed, and C. Sun. 2017. Hoxa5 increases mitochondrial apoptosis by inhibiting Akt/mTORC1/S6K1 pathway in mice white adipocytes. Oncotarget 8:95332-95345. https:/ /doi.org/10.18632/oncotarget.20521.

Geng, J. G. 2001. Directional migration of leukocytes: Their pathological roles in inflammation and strategies for development of anti-inflammatory therapies. Cell Res. 11:85-88. https://doi.org/ 10.1038/sj.cr.7290071.

Guidry, A. J., C. N. O'Brien, and L. W. Douglass. 1998. A bovine mammary endothelial/epithelial cell culture model of the blood/ milk barrier. Can. J. Vet. Res. 62:117-121.

Günther, J., K. Esch, N. Poschadel, W. Petzl, H. Zerbe, S. Mitterhuemer, H. Blum, and H. M. Seyfert. 2011. Comparative kinetics of Escherichia coli- and Staphylococcus aureus-specific activation of key immune pathways in mammary epithelial cells demonstrates that $S$. aureus elicits a delayed response dominated by interleukin-6 (IL-6) but not by IL-1A or tumor necrosis factor alpha. Infect. Immun. 79:695-707. https://doi.org/10.1128/IAI.01071-10.

Hu, D. L., and A. Nakane. 2014. Mechanisms of staphylococcal enterotoxin-induced emesis. Eur. J. Pharmacol. 722:95-107. https://doi .org/10.1016/j.ejphar.2013.08.050.

Huang, S., J. M. Rutkowsky, R. G. Snodgrass, K. D. Ono-Moore, D. A. Schneider, J. W. Newman, S. H. Adams, and D. H. Hwang. 2012. Saturated fatty acids activate TLR-mediated proinflammatory signaling pathways. J. Lipid Res. 53:2002-2013. https://doi .org/10.1194/jlr.D029546.

Jeong, W., H. Bae, W. Lim, F. W. Bazer, H. Lee, and G. Song. 2017. The functional effects and mechanisms by which fibroblast growth 
factor 2 (FGF2) controls bovine mammary epithelial cells: Implications for the development and functionality of the bovine mammary gland. J. Anim. Sci. 95:5365-5377. https://doi.org/10.2527/ jas2017.1877.

Kerro Dego, O., J. E. van Dijk, and H. Nederbragt. 2002. Factors involved in the early pathogenesis of bovine Staphylococcus aureus mastitis with emphasis on bacterial adhesion and invasion. A review. Vet. Q. 24:181-198. https://doi.org/10.1080/01652176.2002 .9695135 .

Kim, K. W., J. Im, J. H. Jeon, H. G. Lee, C. H. Yun, and S. H. Han. 2011. Staphylococcus aureus induces IL- $1 \beta$ expression through the activation of MAP kinases and AP-1, CRE and NF- $\kappa \mathrm{B}$ transcription factors in the bovine mammary gland epithelial cells. Comp. Immunol. Microbiol. Infect. Dis. 34:347-354. https://doi.org/10 $.1016 /$ j.cimid.2011.04.004.

Kobayashi, K., and H. Kumura. 2011. Distinct behavior of claudin-3 and -4 around lactation period in mammary alveolus in mice. Histochem. Cell Biol. 136:587-594. https://doi.org/10.1007/s00418 -011-0863-6.

Kot, B., P. Szweda, A. Frankowska-Maciejewska, M. Piechota, and K. Wolska. 2016. Virulence gene profiles in Staphylococcus aureus isolated from cows with subclinical mastitis in eastern Poland. J. Dairy Res. 83:228-235. https://doi.org/10.1017/S002202991600008X.

Lamkanfi, M., and V. M. Dixit. 2010. Manipulation of host cell death pathways during microbial infections. Cell Host Microbe 8:44-54. https://doi.org/10.1016/j.chom.2010.06.007.

Li, C. M., L. Li, K. L. Chen, Y. R. Wang, F. X. Yang, and G. L. Wang. 2019. UFL1 alleviates lipopolysaccharide-induced cell damage and inflammation via regulation of the TLR4/NF- $\kappa \mathrm{B}$ pathway in bovine mammary epithelial cells. Oxid. Med. Cell. Longev. 2019:6505373. https://doi.org/10.1155/2019/6505373.

Li, T. M., H. Y. Lu, X. Wang, Q. Q. Gao, Y. X. Dai, J. Shang, and M. Li. 2017. Molecular characteristics of Staphylococcus aureus causing bovine mastitis between 2014 and 2015. Front. Cell. Infect. Microbiol. 7:127. https://doi.org/10.3389/fcimb.2017.00127.

Loeffler, D. A., D. M. Camp, S. Qu, B. L. Beaman, and P. A. LeWitt. 2004. Characterization of dopamine-depleting activity of Nocardia asteroids strain GUH-2 culture filtrate on PC12 cells. Microb. Pathog. 37:73-85. https://doi.org/10.1016/j.micpath.2004.05.001.

Maiuri, M. C., E. Zalckvar, A. Kimchi, and G. Kroemer. 2007. Selfeating and self-killing: Crosstalk between autophagy and apoptosis. Nat. Rev. Mol. Cell Biol. 8:741-752. https://doi.org/10.1038/ nrm2239.

Orrenius, S., P. Nicotera, and B. Zhivotovsky. 2011. Cell death mechanisms and their implications in toxicology. Toxicol. Sci. 119:3-19. https://doi.org/10.1093/toxsci/kfq268.

Piccinini, R. R., V. Tassi, R. Daprà, J. Pilla, B. Fenner, M. F. Carter, and M. F. Anjum. 2012. Anjum. Study of Staphylococcus aureus collected at slaughter from dairy cows with chronic mastitis. J. Dairy Res. 79:249-255. https://doi.org/10.1017/S002202991200009X.

Porter, A. G., and R. U. Jänicke. 1999. Emerging roles of caspase-3 in apoptosis. Cell Death Differ. 6:99-104. https://doi.org/10.1038/sj .cdd.4400476.

Ryman, V. E., N. Packiriswamy, and L. M. Sordillo. 2015. Role of endothelial cells in bovine mammary gland health and disease. Anim. Health Res. Rev. 16:135-149. https://doi.org/10.1017/ S1466252315000158.
Song, J. W., S. J. Yang, S. Shin, K. S. Seo, Y. H. Park, and K. T. Park. 2016. Genotypic and phenotypic characterization of methicillin-resistant staphylococcus aureus isolated from bovine mastitic milk in Korea. J. Food Prot. 79:1725-1732. https://doi.org/ 10.4315/0362-028X.JFP-16-067.

Tang, S. E., C. P. Wu, S. Y. Wu, C. K. Peng, W. C. Perng, B. H. Kang, S. J. Chu, and K. L. Huang. 2014. Stanniocalcin-1 ameliorates lipopolysaccharide-induced pulmonary oxidative stress, inflammation, and apoptosis in mice. Free Radic. Biol. Med. 71:321-331. https://doi.org/10.1016/j.freeradbiomed.2014.03.034.

Tanida, I., T. Ueno, and E. Kominami. 2008. LC3 and autophagy. Methods Mol. Biol. 445:77-88. https://doi.org/10.1007/978-1 $-59745-157-4 \_4$.

Viguier, C., S. Arora, N. Gilmartin, K. Welbeck, and R. O'Kennedy. 2009. Mastitis detection. current trends and future perspectives. Trends Biotechnol. 27:486-493. https://doi.org/10.1016/j.tibtech 2009.05.004.

Wang, D., L. Zhang, C. Yong, M. Shen, T. Ali, M. Shahid, K. Han, X. Zhou, and B. Han. 2017. Relationships among superantigen toxin gene profiles, genotypes, and pathogenic characteristics of Staphylococcus aureus isolates from bovine mastitis. J. Dairy Sci. 100:4276-4286. https://doi.org/10.3168/jds.2016-12405.

Wang, F., Y. Zhao, S. Chen, L. Chen, L. Sun, M. Cao, C. Li, and X. Zhou. 2019. Astragaloside IV alleviates ammonia induced apoptosis and oxidative stress in bovine mammary epithelial cells. Int. J. Mol. Sci. 20:600. https://doi.org/10.3390/ijms20030600.

Wang, S. C., C. M. Wu, S. C. Xia, Y. H. Qi, L. N. Xia, and J. Z. Shen. 2009. Distribution of superantigenic toxin genes in Staphylococcus aureus isolates from milk samples of bovine subclinical mastitis cases in two major diary production regions of China. Vet. Microbiol. 137:276-281. https://doi.org/10.1016/j.vetmic.2009.01.007.

Yadav, A., V. Saini, and S. Arora. 2010. MCP-1: Chemoattractant with a role beyond immunity: A review. Clin. Chim. Acta 411:1570-1579. https://doi.org/10.1016/j.cca.2010.07.006.

Yang, L. R. M., T. E. Froio, A. M. Sciuto, R. Dvorak, and F. W. Alon. 2005. ICAM-1 regulates neutrophil adhesion and transcellular migration of TNF-alpha-activated vascular endothelium under flow. Blood 106:584-592. https://doi.org/10.1182/blood-2004-12-4942.

Zhang, W., X. Li, T. Xu, M. Ma, Y. Zhang, and M. Q. Gao. 2016. Inflammatory responses of stromal fibroblasts to inflammatory epithelial cells are involved in the pathogenesis of bovine mastitis. Exp. Cell Res. 349:45-52. https://doi.org/10.1016/j.yexcr.2016.09 .016 .

Zhao, Y. Y., and J. N. Tang. 2018. Staphylococcal enterotoxin M causes intestine dysfunction via activating inflammation. J. Food Saf. 38:e12465. https://doi.org/10.1111/jfs.12465.

Zhao, Y. Y., A. N. Zhu, J. N. Tang, C. Tang, and J. Chen. 2017. Identification and measurement of staphylococcal enterotoxin M from Staphylococcus aureus isolate associated with staphylococcal food poisoning. Lett. Appl. Microbiol. 65:27-34. https://doi.org/ 10.1111/lam.12751.

\section{ORCIDS}

Yanying Zhao ๑ https://orcid.org/0000-0002-6488-0639 Junni Tang (ํ) https://orcid.org/0000-0001-7442-2394 